\title{
Indonesian oleaginous yeasts isolated from Piper betle and P. nigrum
}

\author{
Kanti $A^{1,2^{*}}$, Sukara $E^{3}$, Latifah $K^{4}$, Sukarno $N^{1}$ and Boundy-Mills $K^{6}$ \\ ${ }^{1}$ Department of Biology, Faculty of Mathemathics and Natural Sciences, Bogor Agricultural University, Darmaga \\ Campus, Bogor 16680, Indonesia, atityeast@gmail.com \\ ${ }^{2}$ Research Center for Biology, Cibinong Science Center, Indonesian Institute of Sciences (LIPI), Jl. Raya Bogor Km \\ 46, Cibinong, Indonesia \\ ${ }^{3}$ Research Center for Biotechnology, Cibinong Science Center, Indonesian Institute of Sciences (LIPI), Jl. Raya Bogor \\ $\mathrm{Km}$ 46, Cibinong, Indonesia \\ ${ }^{4}$ Department of Chemistry, Faculty of Mathemathics and Natural Sciences, Bogor Agricultural University, Darmaga \\ Campus, Bogor 16680, Indonesia \\ ${ }^{5}$ Phaff Yeast Culture Collection, Food Science and Technology, University of California Davis, One Shield Avenue, \\ Davis, CA 95616, USA
}

Kanti A, Sukara E, Kadarusman L, Sukarno N, Boundy-Mills K 2013 - Indonesian oleaginous yeasts isolated from Piper betle and $P$. nigrum. Mycosphere 4(5), 1015-1026, Doi 10.5943/mycosphere/4/5/15

\begin{abstract}
In this study, 71 strains of yeast were isolated from Piper betle and $P$. nigrum. Isolates were identified using sequence analysis of the D1/D2 region of large 26S ribosomal subunit rDNA. They belong to 25 species in 11 genera. Strains Cryptococcus luteolus InaCC Y-265, Candida orthopsilosis InaCC Y-302, and Candida oleophila InaCC Y-306 could accumulate more than 40\% of lipid per $\mathrm{g}$ of cell biomass on a dry weight basis. The fatty acids observed were primarily palmitic acid (C18:1), palmitoleic acid (C16:1), stearic acid (C18:0), oleic acid (C18:1) and linolenic acid (C18:2). The fatty acid profiles suggest that these yeasts may be good candidates for biodiesel production, as they are similar to the fatty acids of plant oils currently used for biodiesel.
\end{abstract}

Key words - Candida orthopsilosis - Candida oleophila - Cryptococcus luteolus - fatty acid

\section{Introduction}

While oleaginous yeasts have been studied for many decades (Meng et al. 2009), the search for new oleaginous yeast strains has intensified in recent years (Peng et al. 2013). This is due a global growing awareness of the environmental, social and political hazards of relying on fossil fuels. Renewable, sustainable alternatives such as biofuels are under development. Intensive work is underway by several groups to explore the economic feasibility of producing microbial oil-based biodiesel from microalgae (Roleda et al. 2013), bacteria, yeasts or filamentous fungi (Meng et al. 2009, Lian et al. 2013). Oleaginous yeasts are strong candidates as some of them have the capacity to accumulate high levels of storage lipids, primarily triacylglycerides (Ratledge 1982). Plant associated microbes are a promising target for various bioprospecting studies (Arnold 2007). The work on searching for oleaginous yeast was started with the isolation of suspected potential microbes from various microbial resources including soil, litter, and marine biota (Abraham \& Srinivasan 1984, Harllen et al. 2012, Meng et al. 2007, Ratledge 1993). 
A small number of oleaginous yeast species have been examined to date. These include basidiomycetous yeast species Cryptococcus albidus, C. curvatus, C. magnus, C. terreus, Guehomyces pullulans, Rhodosporidium diobovatum, $R$. toruloides, $R$. colostri, $R$. glutinis, $R$. gramins, $R$. mucilaginosa and Trichosporon guehoae, and ascomycetous yeast species Lipomyces lipofer, L. starkeyi, L. tetrasporus, and Yarrowia lipotica (Wu et al. 2010, Lin et al. 2011). Several researchers have recently reported discovery of new oleaginous species (Lian et al. 2013, Huang et al. 2013, Wang et al. 2013), whose genetic and physiological diversity will aid in development of industrially viable biofuels technologies. Oleaginous yeasts belong to many taxonomic clades, with some clades such as Lipomyces/Myxozyma being rich in oleaginous species.

Oleaginous yeast are clearly polyphyletic. Of the 1500 known yeast species, most have never been examined to determine whether they are oleaginous. Furthermore, only 5\% of yeast species have been described (Cowan 2000). A search for new oleaginous yeast strains and species should focus on traits oleaginous yeasts have in common. Because many of these species were isolated from plant surfaces (Clément-Mathiu et al. 2008) and soil (Kitcha \& Cheirsilp 2011, Saengea et al. 2011) we chose to focus first on plant surface-associated yeasts.

Yeasts inhabit various ecological niches including living plant, animal, deteriorated wood, soil, litter, and water (Spencer \& Spencer 1997). A search for new oleaginous yeasts is best carried out utilizing skills of both the taxonomist and the biochemist. Yeasts isolated from plant surfaces often are able to utilize a broad variety of carbon sources (Kurtzman \& Fell 2011), which makes these species valuable for conversion of plant biomass hydrolysates to biofuels.

Piper betle and P. nigrum are plants native to South and South East Asia that are used traditionally in cooking, medicine or stimulants, and are high in phenolic compounds. The microorganisms associated with this plant could have unique physiological properties. Aravind et al. (2009) isolated 74 strains of bacteria from these two plant species, demonstrating that this plant supports significant microbial diversity on the plant surface. We used conventional staining techniques to rapidly identify potential oleaginous yeasts including the Sudan Black staining technique for observing intracellular lipid bodies (Thakur et al. 1989), and Nile Red fluorescence staining of lipid bodies (Kimura et al. 2004).

\section{Materials \& Methods}

\section{Yeast strains}

The 71 yeast strains were used in this study were obtained from stem, leaf and flower of $P$. betle and fruit of P. nigrum which were collected from Bali (S $08^{\circ} 21^{\prime} 44.8^{\prime \prime}$, E $\left.114^{\circ} 41^{\prime} 00.1^{\prime \prime}\right)$ and West Java (S 06 .35'54.2”, E 106'47'48.7”), Indonesia. Methods for isolation, maintenance and preservation were carried out based on methods developed by Kurtzman \& Fell (2011). Yeast were isolated by dilution, direct inoculation, membrane filter, and ballistospore fall-methods by using isolation medium containing (in $\mathrm{g} / \mathrm{L}$ ) : malt extract 50, agar 20 and chloramphenicol 0.5 (MEA agar). The Yeast Malt Extract (YM) medium containing (in $\mathrm{g} / \mathrm{L}$ ) : glucose 10, yeast extract 3, malt extract 3, and agar 20 were used as a growth medium. Molecular identification was determined by sequence analysis. D1/D2 region of nuclear large-subunit ribosomal DNA was amplified and sequenced using primers NL1 (GCATATCAATAAGCGGAGGAAAAG) and NL4 (GGTCCGTGTTCAAGACGG), as described by Fell et al. (2000). Sequencing of D1/D2 of LSU rDNA was determined with Big Dye terminator v3.1. Cycle Sequencing Ready Reaction Kit (Applied Biosystems) following the manufacturer's instructions. The LSU gene sequences determined in this study were manually aligned with published sequences of reference strain available from the EMBL/GenBank/DDBJ databases (Altschul et al. 1990).

\section{Evaluation of yeast strains for oleaginous properties}

Purified strains were initially streaked onto YM plates and grown for 2 days at $28^{\circ} \mathrm{C}$. Fresh colonies were then inoculated into $250-\mathrm{mL}$ Erlenmeyer flasks containing $50 \mathrm{~mL}$ modified Pan et al. (2009) medium containing (in g/L) : glucose 20, $\left(\mathrm{NH}_{4}\right)_{2} \mathrm{SO}_{4} 5, \mathrm{KH}_{2} \mathrm{PO}_{4} 1, \mathrm{MgSO}_{4} \cdot 7 \mathrm{H}_{2} \mathrm{O} 0.5$, 
and yeast extract 0.5 and grown at $28^{\circ} \mathrm{C}$ on a rotary shaker at $180 \mathrm{rpm}$ for 2 days. This culture was used as inoculum. Five $\mathrm{mL}$ of inoculum were transferred to $45 \mathrm{~mL}$ (in a $250-\mathrm{mL}$ Erlenmeyer flask) of screening medium contained of nitrogen-limited medium (in g/L) : glucose 40, $\left(\mathrm{NH}_{4}\right)_{2} \mathrm{SO}_{4} 2$, $\mathrm{KH}_{2} \mathrm{PO}_{4} 2, \mathrm{NaH}_{2} \mathrm{PO}_{4} 2, \mathrm{MgSO}_{4} \cdot 7 \mathrm{H}_{2} \mathrm{O} 1.5$ and yeast extract 0.5 , supplemented with a 100 -fold diluted trace element solution ( $\mathrm{Wu}$ et al. 2010). The trace element solution contained (in $\mathrm{g} / \mathrm{L}$ ) : $\mathrm{CaCl}_{2} .2 \mathrm{H}_{2} \mathrm{O} 4.0, \mathrm{FeSO}_{4} .7 \mathrm{H}_{2} \mathrm{O} 0.55$, citric acid $\mathrm{H}_{2} \mathrm{O} 0.52, \mathrm{ZnSO}_{4} .7 \mathrm{H}_{2} \mathrm{O} 0.10, \mathrm{MnSO}_{4} \cdot \mathrm{H}_{2} \mathrm{O} 0.076$, and $100 \mu \mathrm{l}$ of $18 \mathrm{M} \mathrm{H}_{2} \mathrm{SO}_{4}$. The medium was sterilized at $121{ }^{\circ} \mathrm{C}$ for $15 \mathrm{~min}$ (Wu et al. 2011). The culture was incubated on a rotary shaker at $180 \mathrm{rpm}$ and $28^{\circ} \mathrm{C}$ for 5 days. Duplicate samples were analyzed for dry mass, percentages of lipids, and residual glucose as described below. The lipid concentration of yeast broth was determined from a standard curve obtained by plotting absorbance against the corresponding lipid concentration determined by the conventional method of acid hydrolysis followed by solvent extraction and gravimetric estimation. Forty $\mathrm{mg}$ samples were extracted with $3 \mathrm{ml}$ of chloroform/methanol $(1 / 2, \mathrm{v} / \mathrm{v})$ by vortexing $(1 \mathrm{~min})$ and centrifugating at $2057 \mathrm{~g}$ for $15 \mathrm{~min}$ at room temperature. The supernatants were collected and residues reextracted twice with $2 \mathrm{ml}$ of chloroform/ methanol $(1 / 1, \mathrm{v} / \mathrm{v})$ by centrifugation as stated above. All the supernatants were pooled together, filtered with Whatman filter No. 1 (Whatman, USA), and washed with $2 \mathrm{ml}$ of Milli-Q water, followed by centrifugation at $2057 \mathrm{~g}$ for $5 \mathrm{~min}$. The lower organic phases were collected and evaporated to dryness under nitrogen and total lipid contents were determined gravimetrically. To confirm lipid accumulating capacity, the Nile Red staining were also conducted following Sitepu et al. (2012).

\section{Determination of lipid content}

Total lipid was determined following the method of Xue et al. (2010). GC-17-A gas chromatography (Shimadzu, Japan) was used for raw lipid and biodiesel analysis. The GC was equipped with a DB-1ht capillary column $(30 \mathrm{~m} \times 0.25 \mathrm{~mm}$; J\&W Scientific, USA) and a flame ionizing detector (FID). The temperatures of the injector and detector were set at 350 and $360^{\circ} \mathrm{C}$, respectively. The profile of the column temperature was as follows: raised from 100 to $180^{\circ} \mathrm{C}$ at $15^{\circ} \mathrm{C} / \mathrm{min}$, raised to $230^{\circ} \mathrm{C}$ at $10^{\circ} \mathrm{C} / \mathrm{min}$, and finally raised to $330^{\circ} \mathrm{C}$ at $20^{\circ} \mathrm{C} / \mathrm{min}$ and maintained for 5 min. Helium was used as the carrier gas. Heptadecanoic acid methyl ester purchased from Sigma was used as an internal standard (Nie et al. 2006).

\section{Determination of yeast dry mass}

Portions of 2-mL cultures were harvested by centrifugation at $5000 \times \mathrm{g}$ for $5 \mathrm{~min}$. Harvested biomass was washed twice with $5 \mathrm{~mL}$ of distilled water and then dried at $60^{\circ} \mathrm{C}$ to constant mass. The biomass was determined gravimetrically.

\section{Lipid composition analysis}

The total lipid concentration was determined by gas chromatographic analysis of the total fatty acids directly transmethylesterified from dried cell (Kumon et al. 2002). One mL of $10 \%$ methanolic $\mathrm{HCl}$ and $0.5 \mathrm{ml}$ methylene chloride were added to the dried biomass and placed at $60^{\circ} \mathrm{C}$ for $3 \mathrm{~h}$ for direct methylesterification. The reaction was stopped by the addition of $2 \mathrm{ml}$ saturated $\mathrm{NaCl}$ solution and $1 \mathrm{ml}$ hexane. The resultant methyl esters recovered in the hexane layer were then applied to a gas chromatograph (GCMS-QP 2010-Ultra; Shimadzu, Kyoto, Japan) equipped with a FAMEWAX capillary column (30 $\mathrm{m} \times 0.25 \mathrm{~mm}$ i.d., GL Science, Tokyo, Japan) under temperature programming $\left(150-250^{\circ} \mathrm{C}\right.$ at $5^{\circ} \mathrm{C} / \mathrm{min}$ increments). Peanut oil (Nacalai Tesque, Kyoto, Japan) was transmethylesterified and used as the reference material.

\section{Results}

Our study proved that $P$. betle and $P$. nigrum is also a good source for oleaginous yeasts. Numerous yeast species were isolated from various plant parts of $P$. betle and $P$. nigrum collected from Bali (Table 1) and from leaf and flower of P. betle collected from West Java (Table 2) and the list of taxa isolated (Table 3 ). 


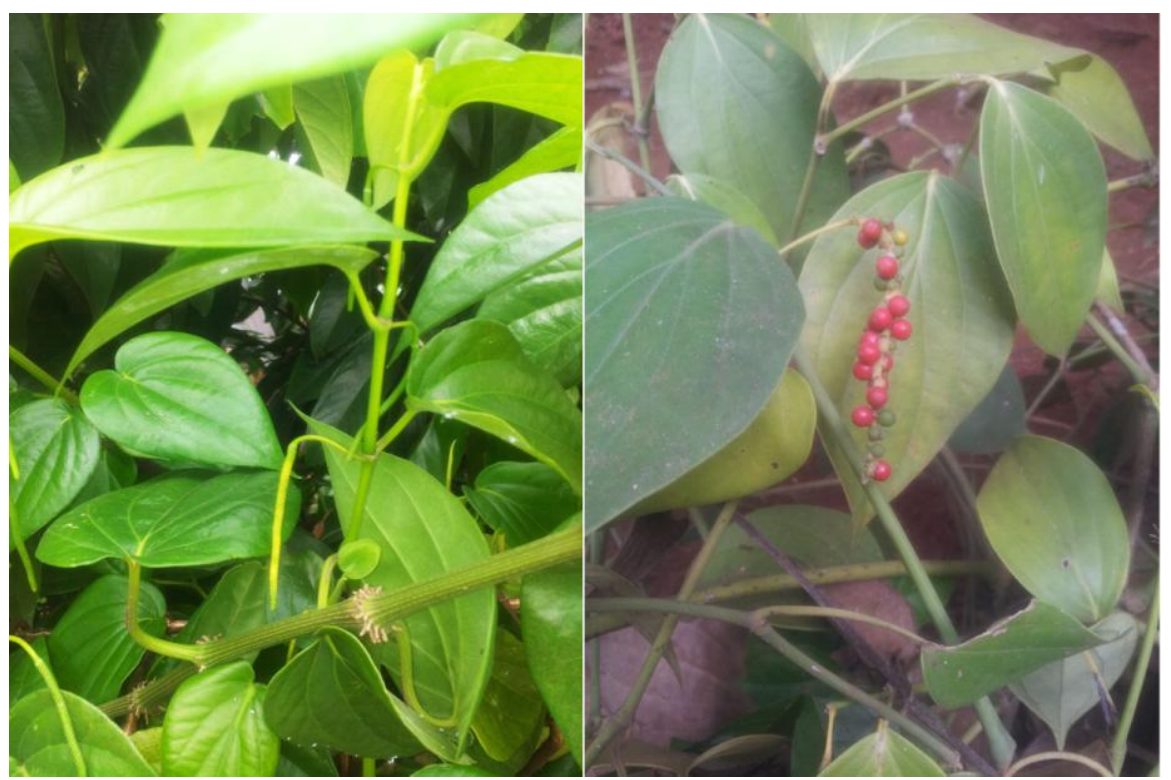

Fig. 1 - Morphology of Piper betle. A and Piper nigrum. B used as microbial sources, obtained from Bali and West Java, Indonesia

Table 1 Number of genera, species and strains of oleaginous yeasts isolated from Piper nigrum and $P$. betle collected from Bali

\begin{tabular}{ccccccc}
\hline \multirow{2}{*}{ Sources } & \multicolumn{3}{c}{ Piper nigrum } & \multicolumn{3}{c}{ Piper betle } \\
\cline { 2 - 7 } & $\begin{array}{c}\text { No. of } \\
\text { Genera }\end{array}$ & $\begin{array}{c}\text { No. of } \\
\text { Species }\end{array}$ & $\begin{array}{c}\text { No. of } \\
\text { Strains }\end{array}$ & $\begin{array}{c}\text { No. of } \\
\text { Genera }\end{array}$ & $\begin{array}{c}\text { No. of } \\
\text { Species }\end{array}$ & $\begin{array}{c}\text { No. of } \\
\text { Strains }\end{array}$ \\
\hline Flower & - & - & - & - & - & - \\
Fruit & 2 & 2 & 6 & - & - & - \\
Leaf & 3 & 4 & 4 & 6 & 11 & 28 \\
Stem & 2 & 2 & 4 & 3 & 4 & 5 \\
Total Number & 7 & 8 & 14 & 9 & 15 & 33 \\
\hline
\end{tabular}

Table 2 Number of species and strains of oleaginous yeasts isolated from Piper betle collected from West Java

\begin{tabular}{cccc}
\hline \multirow{2}{*}{ Sources } & \multicolumn{3}{c}{ Piper betle } \\
\cline { 2 - 4 } & No. of Genera & No. of Species & No. of Strains \\
\hline Leaf & 7 & 13 & 21 \\
Flower & 2 & 3 & 3 \\
\hline
\end{tabular}

The isolation was immediately followed by Sudan Black staining techniques to rapidly identify potential oleaginous yeast (Thakur et al. 1989), and sensitive intracellular lipid body quantification through determination of fluorescent intensity of accumulated lipid bodies, tryacylglycerol, using Nile Red (Kimura et al. 2004; Sitepu et al. 2012)

A total number of 71 strains were analyzed for lipid content. Out of 71 isolates analyzed, 34 of them had the ability to accumulate lipids greater than $20 \%(\mathrm{w} / \mathrm{w})$ of dry cell weight. Some of them could even accumulate more than $40 \%$, as illustrated on Fig. 2. The accumulation of lipid varies among the genera and among strains in the species group. The range of lipid accumulation is from 5.4\% (Rhodosporidium paludigenum InaCC Y-249) to over $42.80 \%$ (Cryptococcus luteolus InaCC Y-265). Lipid production is clearly growth associated. The total biomass produced $(\mathrm{g} / \mathrm{L}$ fermentation broth) varies widely from $2.5 \mathrm{~g} / \mathrm{L}$ (Debaryomyces subglobosus InaCC Y-297) to 10.9 $\mathrm{g} / \mathrm{L}$ (Candida oleophila InaCC Y-306). 
Table 3 List of genera, species and Indonesian Culture Collection (InaCC) strain number of oleaginous yeasts isolated from Piper nigrum and P. betle of Bali and West Java, Indonesia

\begin{tabular}{|c|c|c|}
\hline Genera & Species & Strains No. Code \\
\hline Aureobasidium & Aureobasidium pullulans & InaCC Y-263 \\
\hline Bullera & Bullera coprosmaensis & InaCC Y-266 \\
\hline \multirow{6}{*}{ Candida } & Candida azyma & InaCC Y-296 \\
\hline & Candida oleophila & InaCC Y-306 \\
\hline & Candida orthopsilosis & InaCC Y-302 \\
\hline & Candida parapsilosis & InaCC Y-303 \\
\hline & Candida saopaulonensis & InaCC Y-304, InaCC Y-305 \\
\hline & Candida quercitrusa & InaCC Y-292; InaCC Y-294; InaCC Y-298; InaCC Y-257 \\
\hline \multirow[t]{7}{*}{ Cryptococcus } & Cryptococcus flavescens & InaCC Y-261; InaCC Y-262; InaCC Y-264 \\
\hline & Cryptococcus laurentii & InaCC Y-278 \\
\hline & Cryptococcus luteolus & InaCC Y-265 \\
\hline & Cryptococcus rajasthanensis & InaCC Y-248 \\
\hline & Cryptococcus taeanensis & InaCC Y-268; InaCC Y-289 \\
\hline & & InaCC Y-275; InaCC Y-281; InaCC Y-291; InaCC Y-286; \\
\hline & Cryptococcus sp. & InaCC Y-287 \\
\hline \multirow[t]{3}{*}{ Debaryomyces } & Debaryomyces hansenii & InaCC Y-293; InaCC Y-295; InaCC Y-301 \\
\hline & Debaryomyces subglobosus & InaCC Y-297; InaCC Y-299; InaCC Y-256 \\
\hline & Debaryomyces fabryi & InaCC Y-300 \\
\hline \multirow[t]{3}{*}{ Pseudozyma } & Pseudozyma aphidis & InaCC Y-273; InaCC Y-288 \\
\hline & Pseudozyma hubeiensis & $\begin{array}{l}\text { InaCC Y-277; InaCC Y-274; InaCC Y-282; InaCC Y-240; } \\
\text { InaCC Y-283; InaCC Y-270 }\end{array}$ \\
\hline & Pseudozyma rugulosa & InaCC Y-267; InaCC Y-269 ; InaCC Y-290 \\
\hline Rhodosporidium & Rhodosporidium paludigenum & $\begin{array}{l}\text { InaCC Y-231; InaCC Y-235; InaCC Y-236; InaCC Y- } \\
\text { 249; InaCC Y-234; InaCC Y-247; InaCC Y-246; InaCC Y- } \\
\text { 280; InaCC Y-238; InaCC Y-242; InaCC Y-245; InaCC } \\
\text { Y-252; InaCC Y-254; InaCC Y-259 }\end{array}$ \\
\hline Rhodotorula & Rhodotorula sp. & InaCC Y-279 \\
\hline Sporidiobolus & Sporidiobolus ruineniae & $\begin{array}{l}\text { InaCC Y-232; InaCC Y-233; InaCC Y-237; InaCC Y-250; } \\
\text { InaCC Y-239; InaCC Y-241; InaCC Y-243; InaCC Y-244; } \\
\text { InaCC Y-251; InaCC Y-253; InaCC Y-255 }\end{array}$ \\
\hline Sporobolomyces & Sporobolomyces poonsookiae & InaCC Y-258 \\
\hline Wickerhamomyces & Wickerhamomyces anomalus & InaCC Y-260 \\
\hline
\end{tabular}

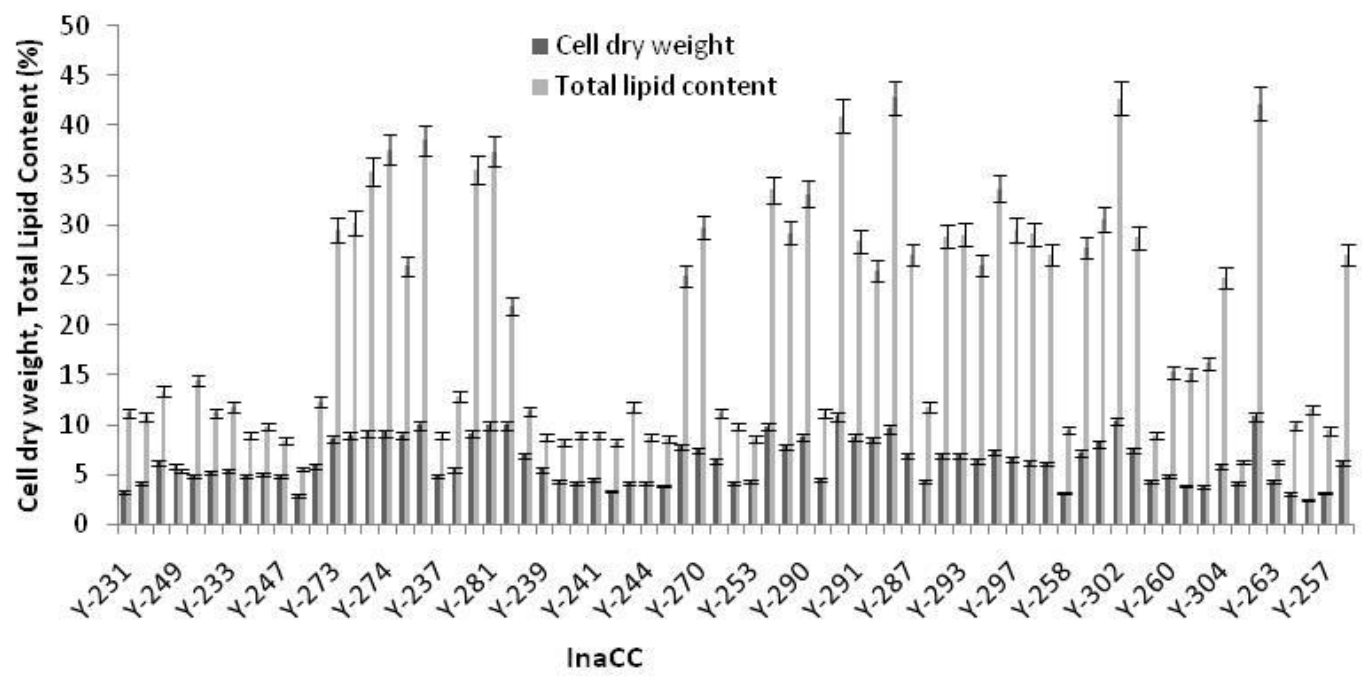

Fig. 2 - The accumulation of lipid (\%, w/w; g of lipid per dry $100 \mathrm{~g}$ of cell biomass) and the production of cell biomass (dry weight in $\mathrm{g} / \mathrm{L}$ of cultural broth) by 71 strains of oleaginous yeasts isolated from Piper nigrum and P. betle obtain from Bali and West Java, Indonesia 
Production of biomass and the accumulation of lipid were diverse among species of the same genus and even strains of the same species. The range of biomass production and lipid accumulation for Debaryomyces are illustrated in Fig. 3, while the range of biomass production and accumulation of lipid for Rhodosporidium is illustrated in Fig. 4, for Sporodiobolus in Fig. 5, and for Pseudozyma is in Fig. 6.

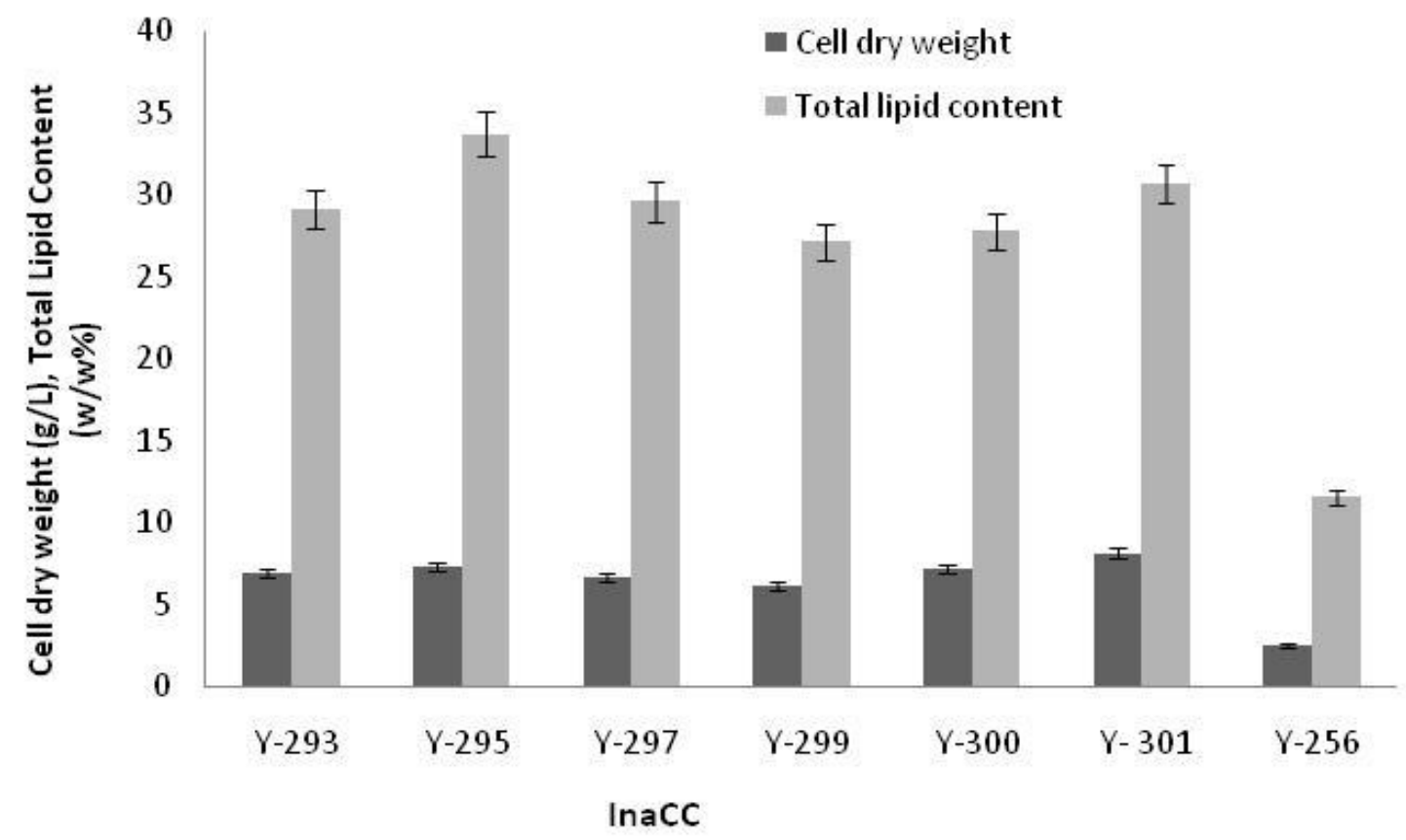

Fig. 3 - The accumulation of biomass and lipid by strains of the genus Debaryomyces

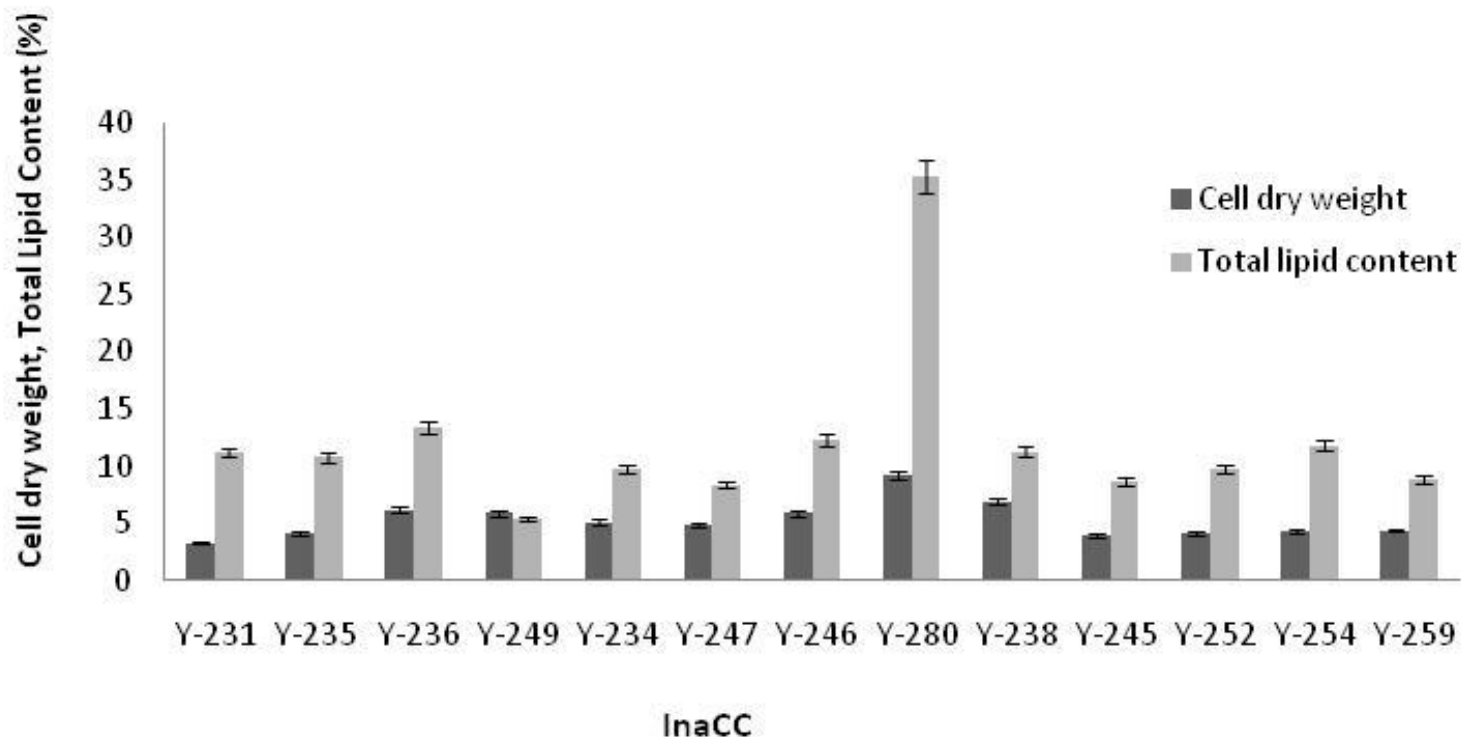

Fig. 4 - The accumulation of biomass and lipid by strains within the genus Rhodosporidium 


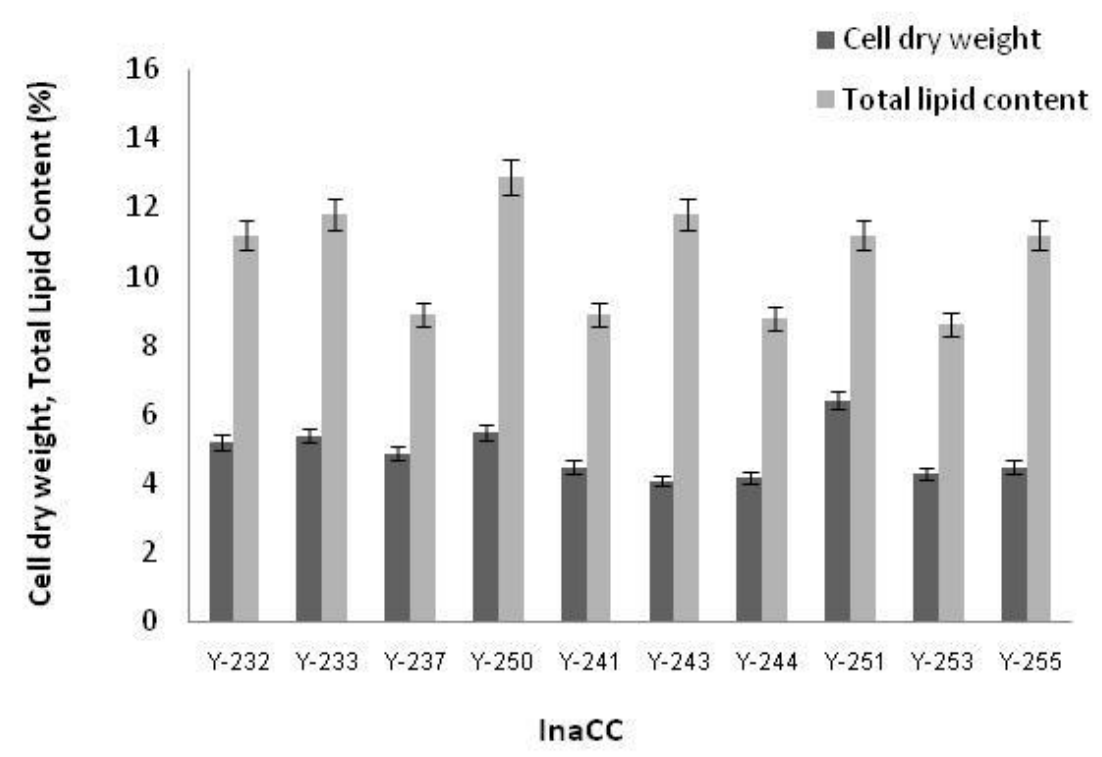

Fig. 5 - The accumulation of biomass and lipid by strains within the genus Sporodiobolus

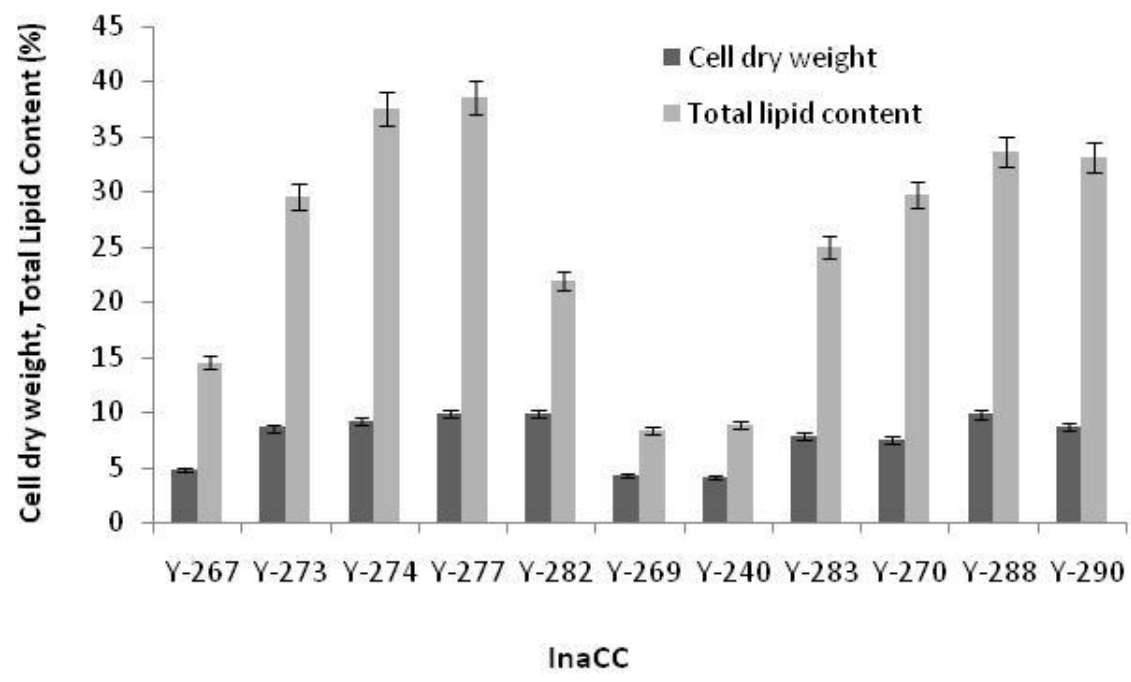

Fig. 6 - The accumulation of biomass and lipid by strains within the genus Pseudozyma

The lipid content of strains of the same species or genus was quite variable. Two out of ten strains of Candida were able to accumulate lipid more than $40 \%$ of dry cell weight, namely Candida azyma InaCC Y-296 and Candida oleophila InaCC Y- 306. The remaining eight strains were poorer at lipid accumulation. Among 13 strains of Cryptococcus only one strain, Cryptococcus luteolus InaCC Y-265 could accumulate more than 40\% lipid. The remaining 12 strains accumulated lipid from 8.9 to $37.38 \%$. Six out of seven Debaryomyces strains were able to accumulate lipid between 27 and 33\%. The lipid accumulation by Pseudozyma are similar to Candida and Cryptococcus. Meanwhile, Rhodosporidium paludigenum InaCC Y-280 has the ability to produce $35 \%$ lipid, but the remaining strains have low capability in accumulating lipid. No strain of Sporidiobolus ruineniae was a good lipid accumulator (Fig. 5).

GC-MS analysis showed that most of the lipid is composed of C 18:1 and C 18:0 (Table 4), indicating that Bullera coprosmaensis InaCC Y-266, Cryptococcus luteolus InaCC Y-265, Candida orthopsilosis InaCC Y-302 and Candida oleophila InaCC Y-306 are good candidates for biofuel development. 
Table 4 Lipid composition of selected oleaginous yeasts

\begin{tabular}{|c|c|c|c|c|c|c|c|c|c|c|c|}
\hline \multirow[t]{2}{*}{ Strains code } & \multirow[t]{2}{*}{$\begin{array}{l}\text { Total } \\
\text { lipid } \\
(\%)\end{array}$} & \multirow[t]{2}{*}{$\begin{array}{l}\text { Dry } \\
\text { weight } \\
\text { (g/L) }\end{array}$} & \multicolumn{9}{|c|}{ Relative fatty acid composition $(\%, w t / w t)$} \\
\hline & & & $14: 0$ & $\begin{array}{l}\text { 16:0 } \\
\text { Palmitic }\end{array}$ & $16: 1$ & $\begin{array}{l}\text { 18:0 } \\
\text { Stearic }\end{array}$ & $\begin{array}{l}\text { 18:1 } \\
\text { Oleic }\end{array}$ & $18: 2$ & $18: 3$ & 20:0 & 22:0 \\
\hline InaCC Y-302 & 42.78 & 5.8 & 1.3 & 18.9 & 6.9 & 17.2 & 38.4 & 11.3 & 1.6 & 1.9 & 1.2 \\
\hline InaCC Y-306 & 42.23 & 5.9 & 1.1 & 16.9 & 7.2 & 24.3 & 41.6 & 6.9 & 1.1 & 1.1 & 1.3 \\
\hline InaCC Y-265 & 42.80 & 5.8 & 1.1 & 16.9 & 7.2 & 24.3 & 38.5 & 6.9 & 1.1 & 1.1 & 1.3 \\
\hline InaCC Y-266 & 40.98 & 5.7 & - & 14.8 & 6.9 & 19.8 & 47.4 & 5.8 & 1.3 & 1.2 & 1.3 \\
\hline
\end{tabular}

*The lipid content was measured after 72 hours cell cultivation

\section{Discussion}

We report here our preliminary work on isolation and identification of yeast associated with $P$. betle and P. nigrum (Fig.1). A number of microbial strains grow in association with $P$. nigrum and $P$. betle. Those two plants species are known as important medicinal plants. The plants are rich in phenolic substances and traditionally used widely in Asia. Aravind et al. (2009, 2010) demonstrated that diverse bacterial species are associated with $P$. betle and P. nigrum, some of which produce valuable bioactives. Our study clearly indicates that several physiologically and economically important strains of yeast could also be isolated from phenolic rich plant species including $P$. bettle and P. nigrum.

A small number of yeast species have been the subject of study for oil production, most notably Yarrowia lipolytica (reviewed in Beopoulos et al. 2008), which is the subject of numerous patents and whose genome has been sequenced. Yeasts have been intensively explored for their potential in conversion of lignocellulosic hydrolysates to oil for biodiesel (Meng et al. 2009).

Overall, this study indicates that plant associated microbes are an important genetic resource for future biofuel development. Furthermore, many species, and many strains per species, must be examined to identify strains with desirable properties such as lipid accumulation and biomass production.

Oleaginous yeast strains have been obtained from diverse habitats including soil, leaf litter, fish gill, and microalgae (Starkey 1946, Li et al. 2007, Pan et al. 2009, Kitcha \& Cheirsilp 2011, reviewed in Meng et al. 2009).

Rhodosporidium is quite ubiquitous, having been isolated from soil, herbaceous plants, silage, sea water, wood, woodchips, leaf, pine cone, plant litter, and air (Hamamoto et al. 2002). Li et al. (2007), studied oleaginous yeast Rhodosporidium toruloides Y4, using fed-batch culture cultivation after 25 days, obtained a biomass yield of $151.5 \mathrm{~g} \mathrm{l}^{-1}$ and lipid content of $48 \%$ (w/w). When grown in pilot-scale fed-batch cultures in a 15-1 stirred-tank fermentor for $134 \mathrm{~h}$ the biomass obtained was even higher $\left(106.5 \mathrm{~g} \mathrm{l}^{-1}\right)$ and lipid production of $0.54 \mathrm{~g} \mathrm{l}^{-1} \cdot \mathrm{h}^{-1}$. Important process parameters were culture media manipulation, and nutrient feeding mode.

Strains of species in the genus Sporidiobolus have also been isolated from leaf of Malpigea coccigera, garden soil, dead leaf Mangifera indica, leaf of lemon and basidiocarps of Myxarium nucleatum (Valerio et al. 2002). Libkind et al. (2008) evaluated the potential of strains within the family Sporidiobolales to produce fatty acids. They found that while the total fatty acid content of their strains was not in the oleaginous range, certain yeasts did produce valuable metabolites including omega-3 fatty acids. Furthermore, altering the growth medium greatly affected the relative abundance of fatty acids. Further investigation of our yeasts is needed to determine if they also share these valuable properties. The red yeasts, especially members of genus Rhodotorula, have been a target to study the metabolism of fatty acids synthesis, and studies of the link between taxonomic position, lipid accumulation properties, and environmental source (Libkind et al. 2008).

The strain Pseudozyma hubeiensis InaCC Y-277 accumulated $38.57 \%$ lipid by cell dry weight. This genus is known for industrial application such as production of itaconic acid (US Patent 7,479,381), biocontrol of plant pathogens (WO Patent WO/2011/151,819), and oil 
production (US Patent App. 13/224,326). Morita et al. (2011) recently published a description of a novel yeast, Pseudozyma churashimaensis, isolated from sugarcane in Okinawa, Japan. This novel strain produced novel substances including glycolipid biosurfactants, a mixture of mannosylerythritol lipids (MELs), and tri-acetylated derivative (MEL-A2).

Cryptococcus is a polyphyletic genus, with species residing in five orders within Basidiomycota. Oleaginous Cryptococcus species are known within three of these orders. We isolated several strains of Cryptococcus that accumulated high levels of intracellular lipid. Strain Cryptococcus luteolus InaCC Y-248 accumulated $42.80 \%$ lipid (w/w) with total biomass of $9.6 \mathrm{~g}$ (dry weight) per L of culture. The lipid accumulating capability of Cryptococcus, especially Cryptococcus curvatus $\mathrm{O} 3$ is well documented (Zhang et al. 2011). Using glucose and varying nitrogen sources, grown in shake flasks at $30^{\circ} \mathrm{C}$, this strain was able to achieved $51.8 \mathrm{~kg} \mathrm{~m} 3$, with lipid content of about $651 \mathrm{~g} / \mathrm{kg}$. When the yeast was grown in a $30 \mathrm{~L}$ stirred fermentor for $185 \mathrm{~h}$, it produced a cellular biomass containing lipid with lipid productivity of $104.1 \mathrm{~kg} \mathrm{~m}^{3}$. Lipid composition was mainly palmitic acid, stearic acid, oleic acid, and linoleic acid, and hence Cryptococcus curvatus $\mathrm{O} 3$ was proposed as oleaginous yeast for biofuel feedstock.

Seven strains within the species Debaryomyces were isolated. Most species within this genus efficiently assimilate glycerol (Kurztman \& Fell 2011), a by product of biodiesel production. Utilization of this by product is a desirable trait for biodiesel production.

Processes have been developed to utilize yeasts for conversion of wastewater to valueadded products (Chen et al. 2012). The well known oleaginous yeasts Lipomyces starkeyi (Angerbauer et al. 2008), Cryptococcus curvatus (Chi et al. 2011), and Rhodotorula glutinis (Xue et al. 2008) are examples of this. Several organic substances such as volatile fatty acids were converted to phenolic compounds by the oleaginous yeast Cryptococcus albidus (Fei et al. 2011). The ability of several yeasts such as Trichosporon coremiiforme to assimilate volatile organic substances could be an important trait for treatment of wastewater containing alcohols (Xue et al. 2012), which implies that exploration of yeasts from several biotopes is worthwhile.

Microbial culture conditions affect lipid composition, and amount of lipid accumulated inside the cell. Culture conditions can be manipulated for optimization of yeast cell biomass production and lipid accumulation (Chi et al. 2011, Wu et al. 2010, Jin et al. 2012, Li et al. 2007). The information on fatty acid synthesis pathways and effects of culture conditions on lipid accumulation have been generated primarily from intensive studies of two oleaginous yeast species: Yarrowia lipolytica (reviewed in Beopoulos et al. 2009) and Rhodotorula glutinis (Xue et al. 2008).

Storage lipids are located primarly in lipid bodies (Nielsen 2009). The amount of accumulated lipid is affected by multiple factors include carbon source, C/N, C/P, and C/S ratios (Wu et al. 2011) and other abiotic factor such as dissolved oxygen, temperature, growth stage, and genetic characters (Meng et al. 2009), and we observed Cryptococcus luteolus InaCC Y-265, Candida orthopsilosis InaCC Y-302, and Candida oleophila InaCC Y-306 accumulated high lipid when grown aerobically at $30^{\circ} \mathrm{C}$ after 5 days cultivation.

The fatty acids observed (Table 4) were primarily palmitic acid (C18:1), palmitoleic acid (C16:1), stearic acid (C18:0), oleic acid (C18:1) and linolenic acid (C18:2) The fatty acid profiles suggest that these yeasts may be good candidates for biodiesel production, as they are similar to the fatty acids of plant oils currently used for biodiesel (Meng et al. 2007).

There are four foci of microbial lipid research: finding novel oleaginous microbes with high TAG accumulating capacity, obtaining lignocellulosic based microbial biodiesel (Yu et al. 2011, Gong et al. 2012), microbial mediated transesterification (Lai et al. 2005), and searching for novel lipid species with pharmaceutical activities. Discovery of novel oleaginous yeasts will further enhance our knowledge in these areas. Our observations indicate that additional yeast species including Bullera coprosmaensis and Pseudozyma hubeiensisis are also promising for future biofuel industry. Discovery of these new oleaginous species is an important step in developing new knowledge in these areas. 


\section{Acknowledgements}

The authors gratefully acknowledge the encouragement and support of The Indonesian Institute of Sciences and The Ministry of Science Technology for providing the research grant, and to Ms. Beatrix Kurnia Gasong, Ms. Immaculata Ayu Siwi, Ms. Yeni Yuliani and Ms. Anis Mutirani for laboratory analyses.

\section{References}

Abraham MJ, Srinivasan RA. 1984 - Lipid and fatty acid composition of selected fungi grown on whey medium. Jurnal of Food Sciences 49, 950-951.

Altschul S, Gish W, Miller W, Myers E, Lipman D. 1990 - Basic local alignment search tool. Journal of Molecular Biology 215(3), 403-410. doi:10.1016/S0022-2836(05)80360-2.

Angerbauer C, Siebenhofer M, Mittelbach M, Guebitz GM. 2008 - Conversion of sewage sludge into lipids by Lipomyces starkeyi for biodiesel production. Bioresource Technology 99, 3051-3056.

Aravind R, Eapen SJ, Kumar A, Dinu A, Ramana KV. 2010 - Screening of endophytic bacteria and evaluation of selected isolates for suppression of burrowing nematode (Radopholussimilis Thorne) using three varieties of black pepper (Piper nigrum L). Crop Protection 29, 318-324.

Aravind R, Kumar A, Eapen SJ, Ramana KV. 2009 - Endophytic bacterial flora in root and stem tissues of black pepper (Piper nigrum L.) genotype: isolation, identification and evaluation against Phytophthora capsici. Letters in Applied Microbiology 48(1), 58-64.

Arnold AE. 2007 - Understanding the diversity of foliar endophytic fungi: progress, challenges, and frontiers. Fungal Biology Reviews 2, 51-56.

Beopoulos A, Mrozova Z, Thevenieau F, Le Dall MT, Hapala I, Papanikolaou S, Chardot L, Nicaud J. 2008 - Control of Lipid Accumulation in the Yeast Yarrowia lipolytica. Applied and Environmental Microbiology 74(24), 77-79.

Chen X, Huang C, Xiong L, Chen X, Chen Y, Long-long Ma L. 2012 - Oil production on wastewaters after butanol fermentation by oleaginous yeast Trichosporon coremiiforme. DOI: http://dx.doi.org/10.1016/j.biortech.2012.05.023.

Chi Z, Zheng Y, Jiang A, Chen S. 2011 - Lipid production by culturing oleaginous yeast and algae with food waste and municipal wastewater in an integrated process. Applied Biochemistry and Biotechnology 165, 1-12.

Clément-Mathiu G, Chain F, Marchand F, Bélanger RR. 2008 - Leaf and powdery mildew colonization by glycolipid-producing Pseudozyma species. Fungal ecology 1, 69-77.

Cowan DA. 2000. Microbial genome: the untapped resources. Trend in Biotechnology 18, 14-16.

Fei Q, Chang HN, Shang L, Choi J, Kim NJ, Kang JW. 2011 - The effect of volatile fatty acids as a sole carbon source on lipid accumulation by Cryptococcus albidus for biodiesel production. Bioresources Technology 102, 2695-2701.

Fell JW, Boekhout T, Alvaro Fonseca A, Scorzetti G, Statzell-Tallman A. 2000 - Systematics of basidiomycetous yeasts as determined by large-subunit rDNA D1/D2 domain sequence analysis. International Journal of Systematic and Evolutionary Microbiology 50, 13511371.

Gong Z, Qian W, Hongwei S, Cuimin H, Guojie J, Zangbao Z. 2012 - Co-fermentation of Cellobiose and Xylose by Lipomyces starkeyi for lipid production. Bioresources Technology 117, 20-24.

Hamamoto M, Takahiko T, Tamura M. 2002 - Systematic study of basidiomycetous yeasts evaluation of the ITS regions of rDNA to delimit species of the genus Rhodosporidium. FEMS Yeast Research 2, 409-413.

Harllen SA, João P.L. Tozzi , César R.F. Terrasan, Bettiol W. 2012 - Endophytic microorganisms from coffee tissues as plant growth promoters and biocontrol agents of coffee leaf rust. Biological Control 63, 62-67. 
Huang C, Chen X, Xiong L, Yang XY, Xin-de Chen XD, Ma LL, Chen Y. 2013 - Microbial oil production from corncob acid hydrolysate by oleaginous yeast Trichosporon coremiiforme. Biomass and Bioenergy 49, 273-278.

Hubenova Y, MarioMitov M. 2010 - Potential application of Candida melibiosica in biofuel cells. Bioelectrochemistry 78, 57-61.

Jin G, Yang F, Hu C, Shen H, Zhao ZK. 2012 - Enzyme-assisted extraction of lipids directly from the culture of the oleaginous yeast Rhodosporidium toruloides. Bioresources Technology $111,378-382$.

Kimura K, Yamaoka M, and Kamisaka Y. 2004 - Rapid estimation of lipids in oleaginous fungi and yeasts using Nile red fluorescence. Journal of Microbiological Methods 56(3), 331338.

Kitcha S and Cheirsilp B. 2011 - Screening of Oleaginous Yeasts and Optimization for Lipid Production Using Crude Glycerol as a Carbon Source. Energy Procedia 9, $274-282$.

Kumon Y, Yokochi T, Nakahara T, Yamaoka M, Mito K. 2002 - Production of long-chain polyunsaturated fatty acids by monoxenic growth of labyrinthulids on oil-dispersed agar medium. Applied Microbiology and Biotechnology 60, 275-280.

Kurztman and Fell. 2011 - Yeast a Taxonomic Study. The Fifth Edition. Elsivier.

Lai CC, Zullaikah S, Vali SR, Ju YH. 2005 - Lipase-catalyzed production of biodiesel from rice bran oil. Journal of Chemistry Technology and Biotechnology 80(3), 331-337.

Li Y, Zhao Z, Bai F. 2007 - High-density cultivation of oleaginous yeast Rhodosporidium toruloides Y4 in fed-batch culture. Enzyme Microbiology Technology 41, 312-317.

Lian J, Garcia-Perez M, Chen S. 2013 - Fermentation of levoglucosan with oleaginous yeasts for lipid production. Bioresource Technology 133, 183-189.

Lian J, Garcia-Perez, M., Chen, S. 2013 - Fermentation of Levoglucosan with Oleaginous Yeasts for Lipid Production. Bioresource Technology, doi: http://dx.doi.org/10.1016/j.biortech.2013.01.031).

Libkind D, Arts MT, van Broock M. 2008 - Fatty acid composition of cold-adapted carotenogenic basidiomycetous yeasts. Revista Argentina de Microbiología 40, 193-197.

Lin J, Shen H, Tan H, Zhao X, Wu S, Hu C,. Zhao ZK. 2011 - Lipid production by Lipomyces starkeyi cells in glucose solution without auxiliary nutrients. Journal of Biotechnology 152(4), 184-188.

Meng X, Yang J, Xu X, Zhang L, Nie Q, Xian M. 2009 - Review Biodiesel production from oleaginous microorganisms. Renewable Energy 34, 1-5.

Morita T, Ogura Y, Takashima M, Hirose N, Fukuoka T, Imura T, Kondo Y, Kitamoto D. 2011 Isolation of Pseudozyma churashimaensis sp. nov., a novel ustilaginomycetous yeast species as a producer of glycolipid biosurfactants, mannosylerythritol lipids. Journal of Bioscience and Bioengineering 112(2), 137-144.

Nie KL, Xie F, Wang F, Tan TW. 2006 - Lipase catalyzed methanolysis to produce biodiesel: optimization of the biodiesel production. Journal of Molecular Catalysis B : Enzymatic $43,142-147$.

Nielsen J.2009 - Systems biology of lipid metabolism: From yeast to human. FEBS Letters 583, 3905-3913.

Pan LX, Yang DF, Shao L, Lie W, Chen GW. 2009 - Isolation of Oleaginous Yeasts, Food Technology Biotechnology 47(2), 215-220.

Peng W, Huang C, Chen X, Xiong L, Chen X, Chen Y, Maa, L. 2013 - Microbial conversion of wastewater from butanol fermentation to microbial oil by oleaginous yeast Trichosporon dermatis. Renewable Energy 55, 31-34.

Ratledge C. 1982 - Microbial oil and fats: an assessment of their commercial potential. Progress in industrial microbiology 16, 119-206.

Ratledge C. 1993 - Single cell oils: have they a biotechnological future? Trend in Biotechnology $11(7), 278$.

Roleda MY, Slocombe SP 1, Leakey RJG, Day JG, Bell EM, Stanley MS. 2013 - Effects of 
temperature and nutrient regimes on biomass and lipid production by six oleaginous microalgae in batch culture employing a two-phase cultivation strategy. Bioresource Technology 129, 439-449.

Saengea C, Cheirsilpb B, Suksarogea TT, Bourtoomc T. 2011 - Potential use of oleaginous red yeast Rhodotorula glutinis for the bioconversion of crude glycerol from biodiesel plant to lipids and carotenoids. Process Biochemistry 46, 210-218.

Sitepu IR, Ignatia L, A.K. Franz AK, Wong DM,. Faulina SA, M. Tsui M , A. Kanti A, Boundy-Mills K. 2012 - An improved high-throughput Nile red fluorescence assay for estimating intracellular lipids in a variety of yeast species. Journal of Microbiological Methods 91, 321-328.

Spencer JFT, Spencer DM.1997 - Ecology : where yeasts live. In : Spencer JFT, Spencer DM, editors. Yeast in natural and artificial habitats.Berlin : Springer - Verlag: 33-58.

Thakur MS, Prapulla SG, Karanth NG, (1989) - Estimation of intraceHular lipids by the measurement of absorbance of yeast cells stained with Sudan Black B. Enzyme Microbiology Technology 11, 252-254.

Thiru M, Sankh S, Rangaswamy V. 2011 - Process for biodiesel production from Cryptococcus curvatus. Bioresource Technology 102, 10436-10440.

Valerio E, Mario Gadanh M, Jose Paulo Sampaio JP, (2002) - Sporobolomyces odoratus sp. nov., a new species in the Sporidiobolus ruineniae clade. FEMS Yeast Research 2, 9-16.

Wang ZP, Xu HM, Wang GY, Zhe Chi, Chi ZM. 2013 - Disruption of the MIG1 gene enhances lipid biosynthesis in the oleaginous yeast Yarrowia lipolytica ACA-DC 50109. Biochimica et Biophysica Acta 1831, 675-682.

Wu S, Hu C, Jin G, Zhao X, Zhao ZK. 2010 - Phosphate-limitation Mediated Lipid Production By Rhodosporidium toruloides. Bioresource Technology 101, 6124-6129.

Wu S, Zhao X, Shen H, Wang Q, Zhao ZK. 2011 - Microbial Lipid Production by Rhodosporium toruloides Under Sulfate-limited Conditions. Bioresource Technology 102, 1803-1807.

Xue F, Gao B, Zhu Y, Zhang X, Feng W, Tan T. 2010 - Pilot-scale production of microbial lipid using starch wastewater as raw material. Bioresource Technology 10, 6092-6095.

Xue FY, Miao JX, Zhang X, Luo H, Tan TW. 2008 - Studies on lipid production by Rhodotorula glutinis fermentation using monosodium glutamate wastewater as culture medium. Bioresource Technology 99, 5923-5927.

Yu X, Zheng Y, Dorgan KM, Chen S. 2011 - Oil production by oleaginous yeasts using the hydrolysate from pretreatmentof wheat straw with dilute sulfuric acid. Bioresource Technology 102, 6134-6140.

Zhang J, Fang X, Zhu X, Yan Li, Xu H, Zhao B, Chen L, Zhang X. 2011 - Microbial lipid production by the oleaginous yeast Cryptococcus curvatus O3 grown in fed-batch culture. Biomass and Bioenergy 3, 1906-1911. 